\title{
Effect of bed roughness on tsunami-like waves and induced loads on buildings
}

\author{
Davide Wüthrich $^{\mathrm{a}, \mathrm{c}, *}$, Michael Pfister ${ }^{\mathrm{b}}$, Anton J. Schleiss ${ }^{\mathrm{a}}$ \\ ${ }^{a}$ Laboratory of Hydraulic Constructions (LCH), Ecole Polytechnique Fédérale de Lausanne (EPFL), Lausanne, Switzerland \\ ${ }^{\mathrm{b}}$ Civil Engineering Department, Haute Ecole d'Ingénierie et d'Architecture de Fribourg (HEIA-FR, HES-SO), Fribourg, Switzerland \\ ${ }^{c}$ Department of Mathematical Science and Advanced Technology (MAT), Japan Agency for Marine-Earth Science and Technology (JAMSTEC), Yokohama, Japan
}

\section{A R T I C L E I N F O}

\section{Keywords:}

Unsteady flows

Tsunami

Bed roughness

Impact forces

Structural loading

\begin{abstract}
A B S T R A C T
Tsunami, impulse-waves and dam-break waves afflict humanity with casualties and damages. An insight into the flow mechanisms of these waves is important to provide safety and reduce reconstruction costs. This experimental study focuses on the effect of bed roughness on the main hydrodynamic properties of surges propagating on dry bed. In addition, the resulting wave impact forces on buildings with and without openings are studied. Results pointed out that dry bed surges on a rough bed had a lower front celerity and a higher flow depth, resulting into inundation depths during the impact around 20\% higher as compared to the smooth bed. Furthermore, a rough bed induced a lower momentum flux during wave propagation, resulting into lower impact forces exerted on the building. The rough bed configuration also caused shorter impact durations, leading to lower impulse values transferred to the building. Results pointed out that even on rough bed, openings within the buildings linearly reduced impact forces, thus providing some helpful information for the design of safer coastal structures.
\end{abstract}

\section{Introduction}

Catastrophes such as tsunamis, impulse waves and dam-break waves are unsteady flow motions resulting into a sudden rise in flow depth. These events are often associated with human losses and important damages to infrastructures (Chock et al. (2012)). Past events, such as the 2004 Indian Ocean tsunami, the 2011 Tohoku Japan tsunami and the most recent 2018 Sulawesi (Indonesia) tsunami, proved the catastrophic nature of these waves propagating inland. Specific studies have shown that an understanding of the physical phenomenon can lead to a better protection of coastal areas and a reduction of post-tsunamis reconstruction costs (Chock et al. (2012)). Other studies pointed out that buildings based on a specific engineering design perform better under hydrodynamic loading (Thusyanthan and Madabhushi (2008), Wilson et al. (2009)), thus serving as vertical shelters.

\subsection{Previous studies}

Because of their low energy dissipation and long periods, tsunamilike waves propagating inland are commonly reproduced using a dambreak wave with an initial impoundment depth $d_{0}$ (Chanson (2006),
Madsen et al. (2008)). Analytically, dam-break waves are described by the theory of Ritter (1892) through a 1-D solution of the Navier-Stokes equations. A sudden removal of a gate with an infinite reservoir under ideal fluid conditions is assumed, generating a wave propagating over a smooth horizontal surface. Because of these restrictive conditions, the theory of Ritter (1892) remains theoretical and simplifies real conditions. Dressler $(1952,1954)$ and Whitham (1955) introduced the effect of bed roughness for a real fluid.

The characterization of the hydrodynamic wave properties is essential for the design of resilient buildings. Several studies described the celerity $U$ of the propagating wave front, both experimentally (Matsutomi and Okamoto (2010); Shafiei et al. (2016); Wüthrich et al. (2017)) and through field surveys (Rossetto et al. (2007); Fritz and Okal (2008); Chock et al. (2012)). In literature $U$ is commonly expressed as a function of the shallow water wave celerity

$U=\alpha \sqrt{g d_{0}}$

where $d_{0}$ is the initial impoundment depth of the reservoir, $g$ the gravity constant $\left(g=9.81 \mathrm{~m} / \mathrm{s}^{2}\right)$ and $\alpha$ a dimensionless celerity coefficient. The number of formulae available in literature showed that disagreement exists in the evaluation of the wave front celerity (Nistor et al. (2009))

\footnotetext{
* Corresponding author. Department of Mathematical Science and Advanced Technology (MAT), Japan Agency for Marine-Earth Science and Technology (JAMSTEC), Yokohama, Japan.

E-mail addresses: d.wuthrich@uq.edu.au (D. Wüthrich), michael.pfister@hefr.ch (M. Pfister), anton.schleiss@epfl.ch (A.J. Schleiss).
} 
and some values of $\alpha$ are presented in Section 3.2.1. Wüthrich et al. (2018a) performed an in-depth investigation of the inner wave velocity profiles showing shapes typical of open channel flows, in line with the Prandtl power law with an exponent $n=8$ for a bed roughness $f=0.02$ in the form:

$\frac{h}{h_{\mathrm{i}}}=\left(\frac{V}{V_{\mathrm{m}}}\right)^{n}$

where $h_{\mathrm{i}}$ is the total wave height and $V_{\mathrm{m}}$ the depth-averaged velocity above of the boundary layer. For a smooth channel, the boundary layer was limited and the velocity profile could be approximated with a constant value. Recent studies of the behaviour of the boundary layer near the tip of dam-break waves were presented by Nielsen (2018) and Baldock (2018). The depth-averaged in-wave profile velocity $V_{\mathrm{m}}$ had a decelerating behaviour behind the wave front, best described as

$\frac{V_{\mathrm{m}}}{U}=1-c \cdot \tanh \left[b \cdot T \sqrt{\frac{g}{d_{0}}}\right]$

where $U$ is the wave front celerity (function of roughness, Eq. (1) and $T$ the shifted time $\left(T=t-t_{0}\right)$ such that $T=0$ when the wave front reached the measurement location. The empirical parameters $c$ and $b$ were defined by Wüthrich et al. (2018a), for which $c$ had a constant value of 0.6 and $b$ was a function of the initial impoundment depth $d_{0}$.

The impact of tsunami-like waves on impervious free-standing buildings was investigated by various authors, including Cross (1967), Ramsden (1996), Asakura et al. (2000), Arnason et al. (2009), Nouri et al. (2010) and Foster et al. (2017). Current design guidelines for tsunami-resistant buildings are provided by ASCE7-6 (Structural Engineering Institute), 2016, FEMA55, 2000 and CCH (City and County of Honolulu), 2000. Recent numerical studies on the effect of bed roughness on circular columns were performed by Asadollahi et al. (2019). In addition, Nouri et al. (2010), Shafiei et al. (2016) and Ylla Arbós et al., 2018 focused on the effect of building orientation on the resulting horizontal force. Wüthrich et al. (2018b) validated experimentally the theory of Yeh (2007) for which the horizontal force $F_{\mathrm{x}}$ transferred from the wave to the building was proportional to the momentum flux per unit width $\left(M=h V_{\mathrm{m}}{ }^{2}\right)$ of the incoming wave. Thus, for dry bed surges frontally impacting free-standing buildings wihout openings, $F_{\mathrm{x}}$ can be estimated using Eq. (4):

$F_{\mathrm{X}, \mathrm{D}}=\frac{1}{2} \rho C_{\mathrm{R}} B \cdot M=\frac{1}{2} \rho C_{\mathrm{R}} B \cdot\left(h V_{\mathrm{m}}^{2}\right)$

where $\rho$ is the water density $\left(\rho=1000 \mathrm{~kg} / \mathrm{m}^{3}\right), B$ is the transverse building width, $h$ is the reference wave height measured without the building, $M$ is the wave momentum flux per unit width $\left(M=h V_{\mathrm{m}}{ }^{2}\right)$ and $V_{\mathrm{m}}$ is the depth-averaged velocity from Eq. (3) as a function of the impoundment depth $d_{0}$ (Fig. 1). $C_{\mathrm{R}}=2.0$ is the resistance coefficient for the impervious, frontal, squared buildings (FEMA55, 2000, ASCE7-6 (Structural Engineering Institute), 2016), CCH (City and County of Honolulu), 2000). In case of building overtopping Wüthrich et al. (2019) proposed a reduced resistance coefficient $C_{\mathrm{R}}=1.5$.

For permeable buildings with openings, Wüthrich et al. (2018c) proposed a linear relationship between building porosity and the induced horizontal impact forces:

$F_{\mathrm{x}, \mathrm{D}}=\frac{1}{2} \rho \cdot C_{\mathrm{R}} \cdot \Pi \cdot B \cdot h V_{\mathrm{m}}^{2}$

where $\Pi$ is a porosity coefficient defined in Eq. (6) as a function of the porosity on both the front $\left(P_{\mathrm{h}, \text { max }}\right)_{\text {front }}$ and back sides $\left(P_{\mathrm{h}, \max }\right)_{\text {back }}$ of the building. The lateral walls showed no influence on the resulting hydrodynamic load. Note that for impervious buildings $(\Pi=1)$ Eq. (5) is equivalent to Eq. (4).

$\Pi=\left\{1-\min \left[\left(P_{\mathrm{h}, \max }\right)_{\text {front }} ;\left(P_{\mathrm{h}, \max }\right)_{\text {back }}\right]\right\}$

\subsection{Novelty and objectives}

Most previous studies considered smooth channel beds, however these ideal conditions are rarely encountered in coastal areas exposed to tsunami hazards. Nonetheless, bed roughness is responsible for an alteration of the main hydrodynamic properties of the waves and, subsequently, of the loading process against coastal structures. This study provides information on the effect of bed roughness in the design of coastal buildings, namely to

- describe the main hydrodynamic properties of dry bed surges propagating on a bed with enhanced roughness.

- quantify the effect of bed roughness on the wave-induced loading process on buildings with and without openings, in terms of horizontal forces, impulse and cantilever arm.

\section{Experimental set-up}

All tests were carried out in a large-scale facility at Laboratory of Hydraulic Constructions ( $\mathrm{LCH}$ ) of Ecole Polytechnique Fédérale de Lausanne (EPFL) in Switzerland. All dry bed surges were generated using a vertical release technique. The vertical drop of a water volume of $7 \mathrm{~m}^{3}$ from an upper reservoir into a lower reservoir produced waves that were shown to have similar properties to those generated with a classical dam-break technique and thus representative for tsunami-like flows (Fig. 1, Wüthrich et al. (2018a)). Similar techniques were previously used by Chanson et al. (2002), Lukkunaprasit et al. (2009), Meile et al. (2011), Rossetto et al. (2011) and Foster et al. (2017).

The generated waves propagated on a $15.5 \mathrm{~m}$ long horizontal wooden channel with a width $W=1.40 \mathrm{~m}$. Tests under steady flow conditions showed values of a Darcy-Weisbach friction factor $f \approx 0.02$, hereafter referred to as the "smooth" condition. To increase the roughness of the channel bed, an artificial turf (green carpet) was added. The latter had a thickness of $7 \mathrm{~mm}$ and steady state tests indicated $f \approx 0.04$, corresponding to an equivalent sand roughness of around $2.8 \mathrm{~mm}$ (referred to as the "rough" condition). These values are consistent with literature for similar materials (Choufi et al. (2014)).

The development of the generated waves was recorded using 7 nonintrusive Ultrasonic distance Sensors (US) installed along the channel centreline at $x=2.0,10.1,12.1,13.1,13.35,13.6$ and $13.85 \mathrm{~m}$ from the inlet (Fig. 1). The US sensors had a sampling frequency of $12.5 \mathrm{~Hz}$, an accuracy of $\pm 0.5 \mathrm{~mm}$ and a response time of less than $80 \mathrm{~ms}$. Flow velocity (i.e., in-wave velocity) was logged using an Ultrasonic Velocity Profiler (UVP), type DUO-MX SN from Met-Flow (Switzerland). The UVP provided instantaneous velocity profiles along the transducer axis by detecting the Doppler shift frequency of echoed ultrasound as a function of time. A transducer with an emitting frequency of $2 \mathrm{MHz}$ was chosen for the present study. It was located at a distance $x=13.85 \mathrm{~m}$ from the channel inlet, $5 \mathrm{~mm}$ below the channel bottom with an angle of $20^{\circ}$ in the upstream direction (Fig. 1d). A detailed sensitivity analysis led to acquisition frequencies ranging from 12.5 to $55 \mathrm{~Hz}$, with an accuracy of $\pm 10 \mathrm{~mm} / \mathrm{s}$.

For the load analysis, a free-standing building was mounted in the channel, at a distance of $x=14.0 \mathrm{~m}$ from the channel inlet (Fig. 1a). This building had a cubic shape made of aluminium plates with a width, height and length of $B=0.3 \mathrm{~m}$. This resulted in a blockage ratio of $\beta=W / B=4.67$, being sufficient to limit side-wall effects. The building was completely rigid with stiffness values of $0.63-1.69 \cdot 10^{7} \mathrm{~N} / \mathrm{m}$ (model scale) and the dynamic response was thus assumed insignificant. The aluminium cube corresponded to prototype buildings of $9 \mathrm{~m}$ side-length if a geometrical scale factor of 1:30 is assumed. Such dimensions would be typical of residential buildings commonly observed in coastal zones exposed to tsunami hazard.

The total building porosity was varied between $P_{\text {tot }}=0$ (impervious), 34 and 60\% (highly permeable), being visualized in Fig. 2. Additionally, an equivalent porosity $P_{\mathrm{h}, \max }$ was defined as the 


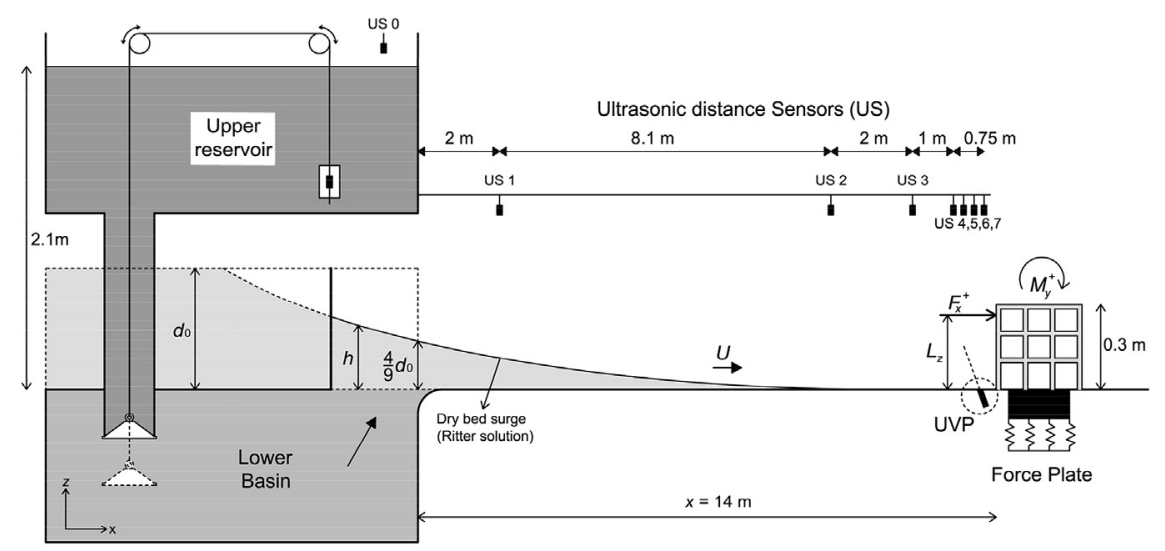

(a)

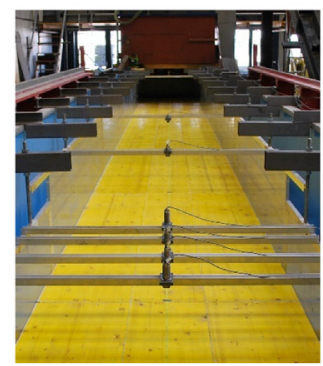

(b)

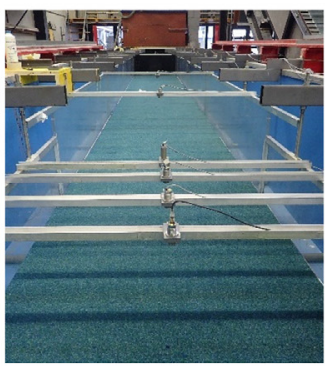

(c)
ULTRASONIC VELOCITY PROFILER (UVP)

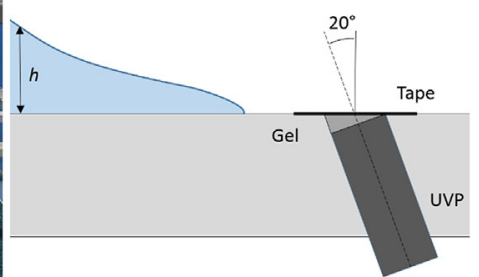

(d)

Fig. 1. (a) Experimental set-up (adapted from Wüthrich et al., 2018c); (b) smooth bed; (c) rough bed; (d) installation of the UVP. [Images by author(s)].

cumulative porosity up to $h=h_{\max }$, being thus dependant on the maximum wave height (measured without the building). Openings were equally distributed on all four sides of the building. The same configurations were previously tested by Wüthrich et al. (2018c) for a smooth channel.

The buildings were assembled on a dynamometric Force-Plate (AMTI MC6-1000), allowing to capture forces and moments in the three main directions with a frequency of $1 \mathrm{kHz}$. Fig. 1 a shows the set-up and the force reference system. All USs and the 6 channels of the Force-Plate were directly connected to a LabVIEW master program, and the synchronization with the UVP-DUO unit was achieved through a Transistor-Transistor Logic (TTL) level $(+5 \mathrm{~V}$, minimum $20 \mathrm{~ns})$ trigger signal, sent when the measurement was launched from the main panel (Wüthrich et al. (2018a)).

\section{Wave hydrodynamics}

The main hydrodynamic properties of the waves on rough channel bed are described and compared herein to those on a smooth bed, previously measured by Wüthrich et al. (2018a). Hence, for this part no building was installed in the channel. Table 1 gives the hydrodynamic properties of the tested surges. Note that $\mathbf{F r}=U /\left(g h_{\text {max }}\right)^{0.5}$ is the Froude number computed with the front celerity $U$ and the maximum wave height $h_{\max }$ without building.

\subsection{Wave profiles}

Dry bed surges represent the first incoming tsunami wave propagating on dry land. Any subsequent wave propagating on wet bed is best reproduced using turbulent bores, whose physical behaviour was shown to be different from dry bed surges (Stoker (1957), Ramsden (1996), Chanson (2004) and Wüthrich et al. (2018a), among others). However, this study only focuses on dry bed surges as wet bed bores are only slightly affected by bed roughness (Wüthrich et al. (2017)).

Surges propagating on a dry smooth bed physically appeared as a continuous raise in flow depth until a maximum water depth $h_{\max }$ is reached. For these, little aeration was observed at the surge tip (Fig. 3a, Wüthrich et al. (2018a)). An enhanced channel roughness (rough bed) caused modified features of the propagating dry bed surges. Fig. $3 \mathrm{~b}$ shows a more aerated surge front compared to the corresponding case on smooth bed. Flow depths are presented in Fig. 4, showing higher values for the rough bed as compared to the smooth bed. One can also notice the later arrival of the surge propagating on rough bed, suggesting a slower front celerity.

In line with the results of Wüthrich et al. (2018a), the longitudinal wave profiles obtained when the dry bed surge reached $x=13.85 \mathrm{~m}$ (location of US 7, criteria $h>0.01 \mathrm{~m}$ ) were compared to the theoretical solutions of Ritter (1892) and Chanson (2009). The smooth bed condition is merely theoretical and the influence of bed friction was

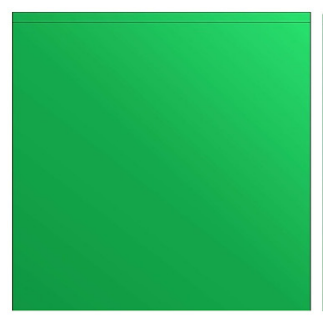

$P_{\text {tot }}=0 \%$ (Impervious)

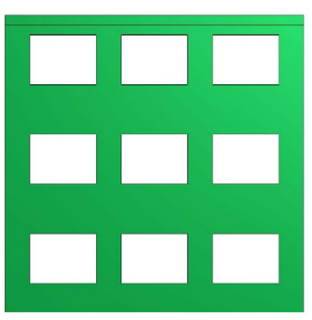

$P_{\text {tot }}=34 \%$

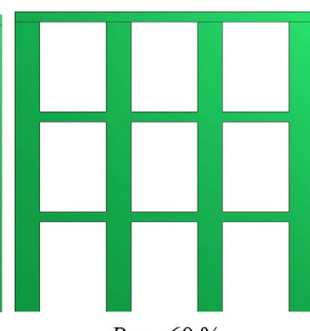

$P_{\text {tot }}=60 \%$

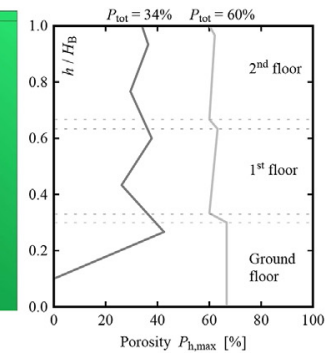

Fig. 2. Building openings configurations (with related total porosity $P_{\text {tot }}$ values), studied in combination with a smooth and a rough channel condition. 
Table 1

Hydrodynamic properties of the dry bed surges without the building.

\begin{tabular}{|c|c|c|c|c|c|c|c|c|}
\hline Wave & Initial bed condition & $f[-]$ & $d_{0}[\mathrm{~m}]$ & $h_{\max }[\mathrm{m}]$ & $U[\mathrm{~m} / \mathrm{s}]$ & $\left(h V_{\mathrm{m}}^{2}\right)_{\max }\left[\mathrm{m}^{3} / \mathrm{s}^{2}\right]$ & Fr & Number of test repetitions \\
\hline WD1 & Dry & 0.02 & 0.40 & 0.132 & 2.35 & 0.29 & 2.06 & 3 \\
\hline WD1 - R & Dry & 0.04 & 0.40 & 0.161 & 1.81 & 0.24 & 1.44 & 2 \\
\hline WD2 & Dry & 0.02 & 0.63 & 0.162 & 3.11 & 0.71 & 2.47 & 3 \\
\hline $\mathrm{WD} 2-\mathrm{R}$ & Dry & 0.04 & 0.63 & 0.191 & 2.50 & 0.62 & 1.83 & 2 \\
\hline WD3 & Dry & 0.02 & 0.82 & 0.181 & 3.56 & 1.22 & 2.67 & 6 \\
\hline WD3 - R & Dry & 0.04 & 0.82 & 0.208 & 2.85 & 0.90 & 2.00 & 3 \\
\hline Min & & 0.02 & 0.40 & 0.132 & 1.81 & 0.24 & 1.44 & 2 \\
\hline Max & & 0.04 & 0.63 & 0.208 & 3.56 & 1.22 & 2.67 & 6 \\
\hline
\end{tabular}

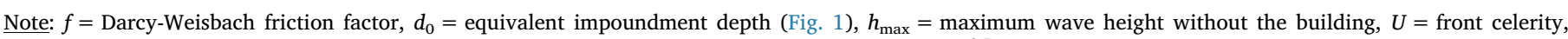
$V_{\mathrm{m}}=$ depth averaged profile velocity (Wüthrich et al., 2018a), and Froude Number Fr $=U /\left(g h_{\max }\right)^{0.5}$.

Table 2

Velocity coefficients $\alpha$ available in literature.

\begin{tabular}{lll}
\hline & Legend & $\alpha$ \\
\hline-- & $\sqrt{g d_{0}}$ & 1.00 \\
- & FEMA55, 2000), Ritter, 1892 & 2.00 \\
- & CCH (City and County of Honolulu), 2000 & - \\
-- & Iizuka and Matsutomi, 2000 & 1.10 \\
-- & Kirkoz, 1983 & $\sqrt{2}$ \\
- & Murty, 1977 & 1.83 \\
- & Bryant, 2008 & 1.67 \\
- & Matsutomi and Okamoto, 2010 & 0.66 \\
& Shafiei et al., 2016 & 1.70 \\
& Wüthrich et al., 2017 & 1.25 \\
\hline
\end{tabular}

implemented by Dressler $(1952,1954)$ and Whitham (1955). The effect of bed roughness on the experimental data is visualized in Fig. 5 and compared to the model presented by Chanson (2009) for $f=0.04$, thus proving the consistency between present measurements, theory and literature.

\subsection{Velocities}

Two velocities are considered herein: (1) wave front celerity $U$, obtained via the US sensors; and (2) in-wave velocity profiles behind the wave front, measured using the UVP probe installed in the channel bottom (Fig. 1d).

\subsubsection{Front celerity}

The wave front celerity $U$ represents a key parameter for the design of resilient structures. It was calculated from the US data as the ratio of the distance between two adjacent sensors and the wave travel time $(U=\Delta x / \Delta t)$. Note that the wave arrival time at a certain US sensor was set when an increase in flow depth of $h>0.01 \mathrm{~m}$ was recorded. Nistor et al. (2009) and Wüthrich et al. (2018a) pointed out that incertitude exists in the evaluation of the front celerity for dry bed surges. For the surge propagating on a smooth bed, a celerity coefficient $\alpha=1.25$ (Eq.

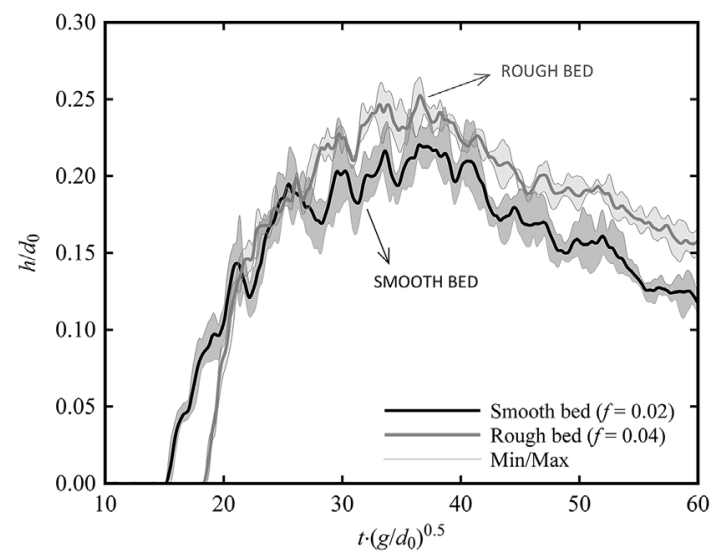

Fig. 4. Average wave profiles for a dry bed surge on smooth and rough beds $\left(d_{0}=0.82 \mathrm{~m}\right)$.

(1) was suggested by Wüthrich et al. (2018a). For dry bed surges on rough bed, present results showed a delayed arrival time (Fig. 4a) associated with a lower wave front celerity, best represented by $\alpha=1.0$. The experimental data are presented in Fig. 6, showing consistency with previous studies.

Among others, Wüthrich et al. (2017) showed that $\alpha$ depends on the friction factor $f$. Fig. 7 shows good agreement between the experimental points and the theories of (1) Dressler (1952,1954), who solved the Saint-Venant equations using a perturbation method assuming a constant friction factor and (2) Whitham (1955), who used an adaptation of the Polhausen Method (Chanson (2004)).

\subsubsection{Velocity profiles}

The installation of a UVP probe within the channel bottom (Fig. 1) allowed to investigate the in-wave velocity profiles. For smooth beds, Wüthrich et al. (2018a) showed the presence of profiles typical of open channel flows, best described by a Prandtl power law with an exponent of $n=8$. (Eq. (2). The higher friction coefficient $f=0.04$ (rough configuration) generated a thicker boundary layer, thus resulting into an exponent $n=7$. At the same normalized time step $T \cdot\left(\mathrm{g} / \mathrm{d}_{0}\right)^{0.5}$ (using

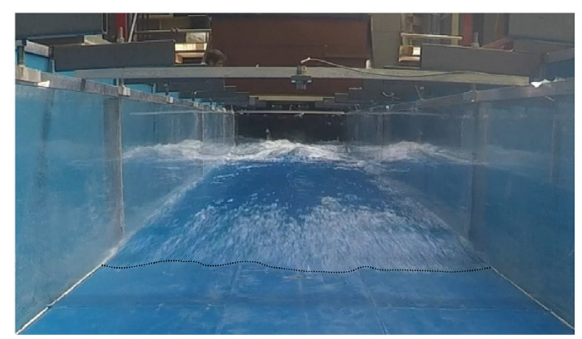

(a) Smooth

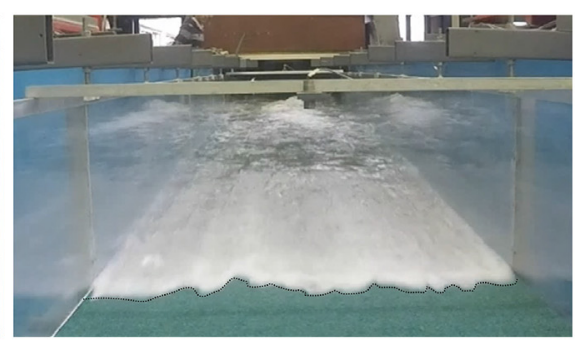

(b) Rough

Fig. 3. Fronts of dry bed surge $\left(d_{0}=0.82 \mathrm{~m}\right)$ on: (a) smooth $(f=0.02)$ and (b) rough bed $(f=0.04)$. [Image by author(s)]. 


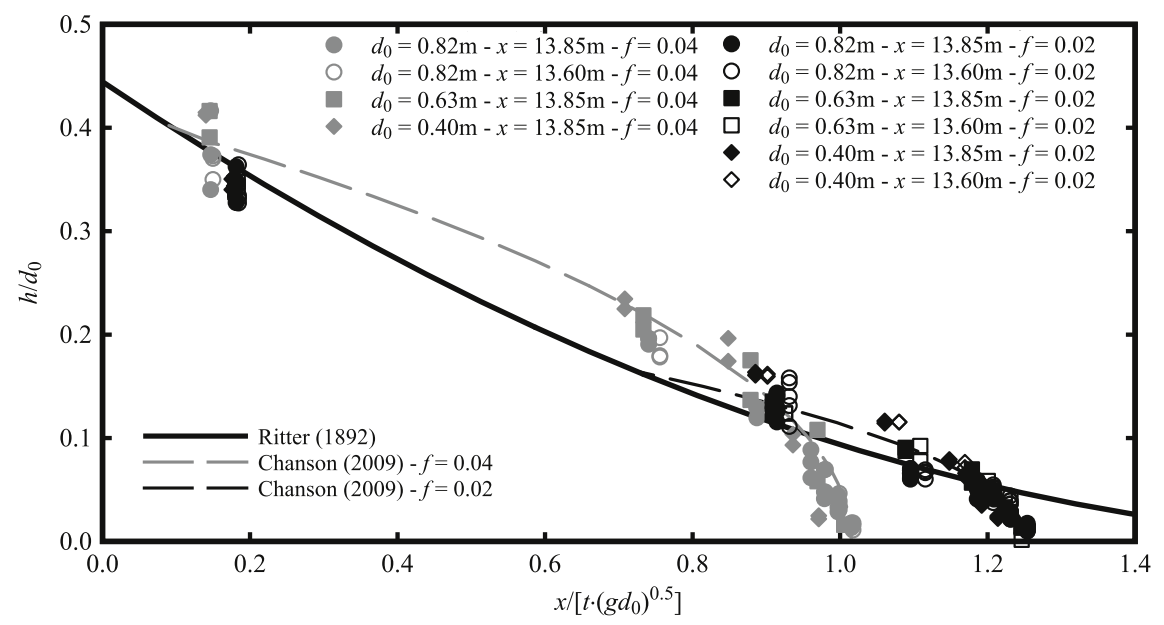

Fig. 5. Comparison of theories of Ritter, 1892 and Chanson, 2009 with test data on dry bed, including both, smooth (black symbols) and rough bed (grey symbols) when the surge tips reaches at $x=13.85$ and $13.60 \mathrm{~m}$. $\left(d_{0}=0.82,0.63\right.$ and $\left.0.40 \mathrm{~m}\right)$.

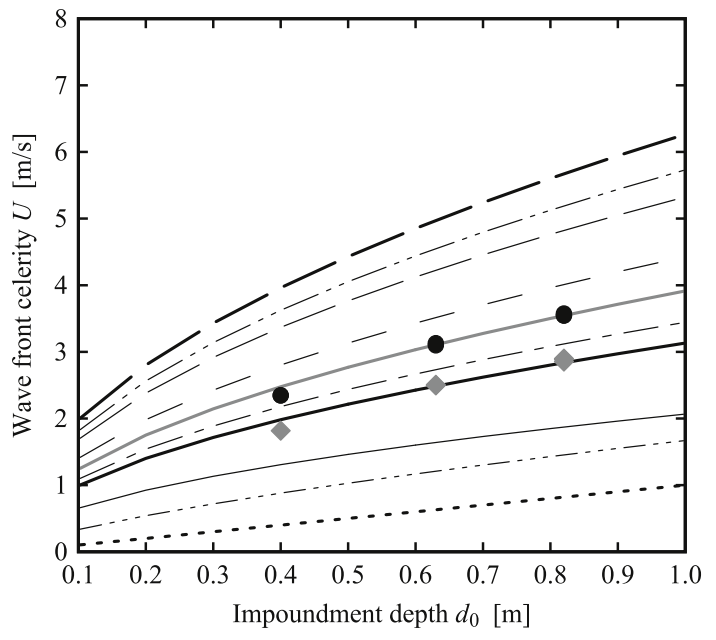

Fig. 6. Comparison of wave front celerity with empirical formulae available in literature (Legend in Table 2).

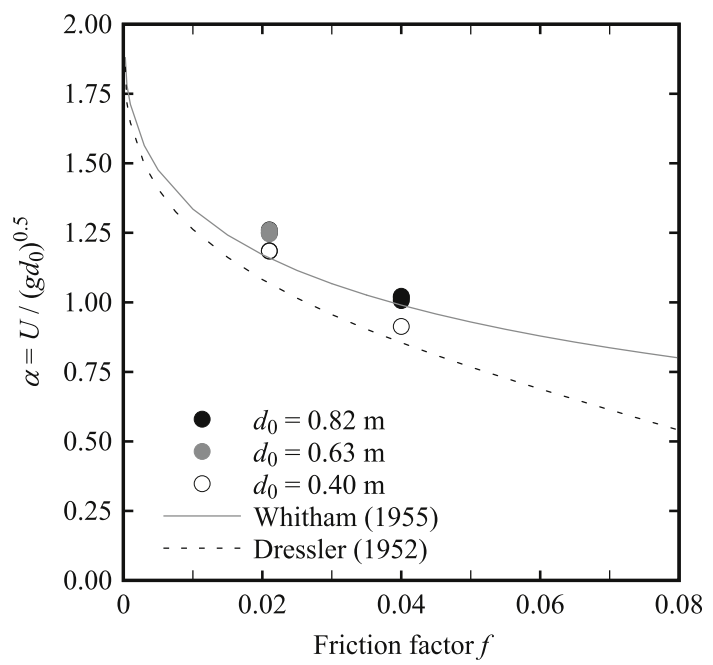

Fig. 7. Comparison of experimental celerity coefficient $\alpha$ for dry bed surges with literature, as a function of bed roughness $f$.

$T=t-t_{0}$, with $T=0$ s as wave arrival time at the measurement location), Fig. 8 shows that for dry bed surges, an enhanced bed roughness generated a reduction in velocity magnitude, associated with higher

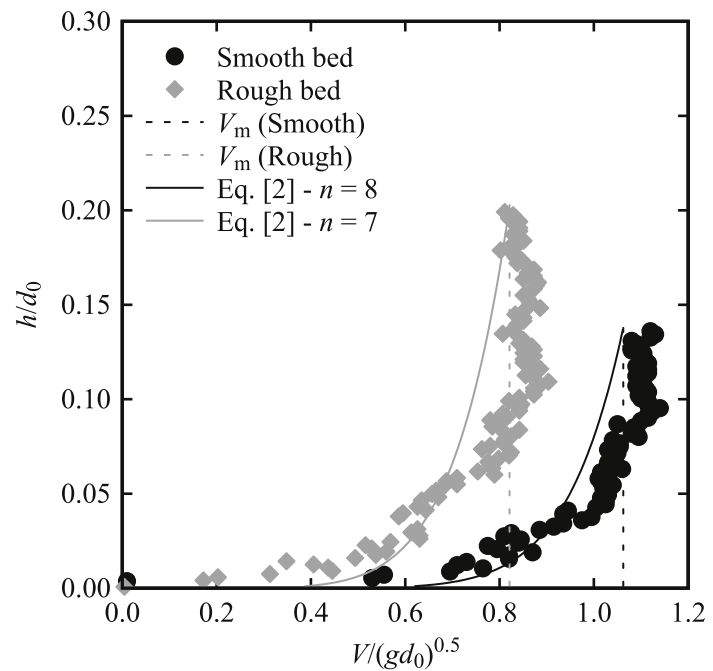

Fig. 8. Velocity profiles for a dry bed surge $\left(d_{0}=0.82 \mathrm{~m}\right)$ on smooth and rough bed at $T \cdot\left(g / d_{0}\right)^{0.5} \approx 22$.

flow depths. This is in line with the findings in Fig. 4.

Similarly to Wüthrich et al. (2018a), depth-averaged velocities $\left(V_{\mathrm{m}}\right)$ had a decelerating behaviour behind the wave front, well described by Eq. (3). for waves propagating on smooth bed. A comparison of the measurements on smooth and rough bed showed little difference in the relative velocity decrease $V_{\mathrm{m}} / U$ (Fig. 9). This implies that Eq. (3). can thus be used to characterize the velocity behaviour behind the wave front also for the waves propagating on a channel with higher roughness values $(f=0.04)$.

These results in terms of hydrodynamic wave properties pointed out some key differences between the smooth and the rough bed configurations, with the enhanced bed roughness resulting into a lower wave front celerity and higher flow depths. The deceleration behind the wave front (Eq. (3).) seemed not to be affected by bed roughness. As a result of these modified flow depths and velocities, a higher bed roughness was responsible for reduced values of the momentum flux $h V_{\mathrm{m}}^{2}$ up to $12-17 \%$ for dry bed surges (Table 1 ).

\section{Wave impact}

To study the wave impact in combination with a rough bed, an impervious (reference) building and two porous buildings ( $P_{\text {tot }}=34 \%$ and $60 \%$, Fig. 2) were tested. The same buildings with a smooth 


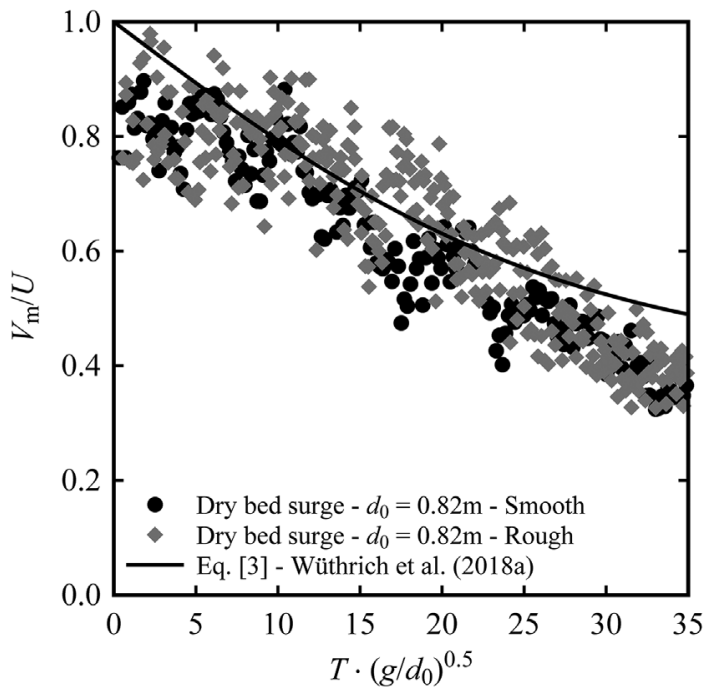

Fig. 9. Normalized in-wave depth-averaged velocity decrease for a dry bed surges propagating on both, smooth and rough bed $\left(d_{0}=0.82 \mathrm{~m}\right)$.

Table 3

Experimental program for configurations with building.

\begin{tabular}{llllll}
\hline Test No. & \multicolumn{2}{c}{ Channel condition } & $\begin{array}{l}\text { Total building } \\
\text { porosity } P_{\text {tot }} \\
{[\%]}\end{array}$ & $\begin{array}{l}\text { Wave type } \\
\text { (Table 1) }\end{array}$ & $\begin{array}{l}\text { Number of } \\
\text { repetitions }\end{array}$ \\
\cline { 2 - 6 } & Type & Roughness & & \\
\hline 1 & Dry & Smooth & 0 & WD1, WD2 & 4 \\
2 & Dry & Rough & 0 & WD1 - R, & 4 \\
& & & & WD2 - R & \\
5 & Dry & Smooth & 60 & WD1, WD2 & 2 \\
6 & Dry & Rough & 60 & WD1 - R, & 4 \\
7 & & & & WD2 - R & \\
8 & Dry & Smooth & 34 & WD1, WD2 & 4 \\
& Dry & Rough & 34 & WD1 - R, & 4 \\
& & & & WD2 - R &
\end{tabular}

Note: Smooth: $f=0.02$; Rough $f=0.04$, where $f$ is the Darcy-Weisbach friction factor.

channel were previously tested by Wüthrich et al. (2018b,c). The experimental program is presented in Table 3.

\subsection{Flow depth}

Visual assessment showed that the impact of dry bed surges propagating over rough beds onto free-standing buildings generated impact splashes (Fig. 10a), followed by a subsequent steadier flow around the building (Fig. 10b). These observations was perfectly in line with those for the same waves propagating over a smooth horizontal bed (Wüthrich et al. (2018b)).

Compared to dry bed surges on smooth bed, those on rough bed

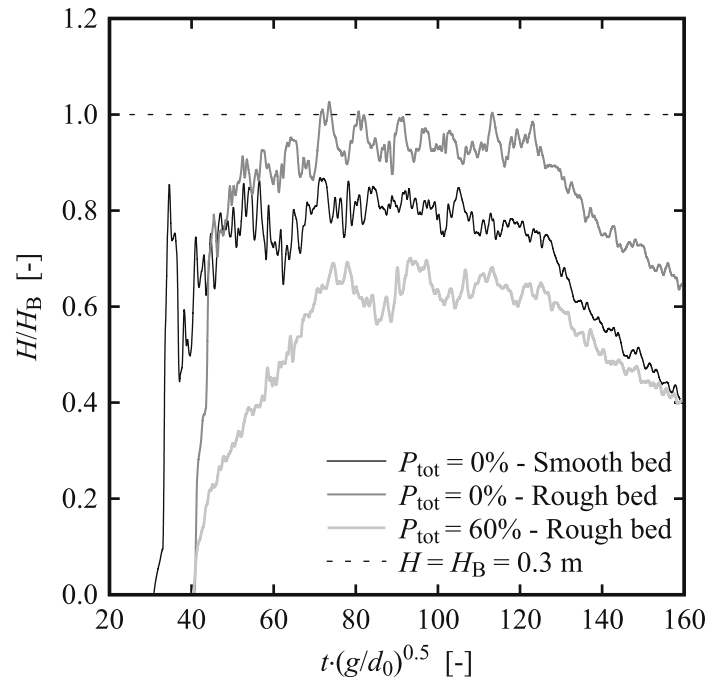

Fig. 11. Normalized flow depths on the upstream side of an impervious $\left(P_{\text {tot }}=0 \%, H_{\mathrm{B}}=0.3\right.$ ) and porous $\left(P_{\text {tot }}=60 \%\right.$ ) building (US7, $x=13.85 \mathrm{~m}$ ) during the impact of a dry bed surge $\left(d_{0}=0.40 \mathrm{~m}\right)$ propagating either on a smooth (WD1) or a rough bed (WD1-R).

showed less splashes and lower run-up heights $H$ during the impact, due to the lower wave front celerity and augmented aeration. The measurements of the flow depths $H$ near the upstream side of the building (US7, $x=13.85 \mathrm{~m}$ ) are presented in Fig. 11a, and showed flow depths some $20 \%$ higher for the rough bed as compared to the smooth bed. Since a rough bed condition is more frequent in practice, vertical shelters should, relatively seen, be taller in order to prevent building overtopping. For permeable buildings with openings (Fig. 10), the flow through the building led to a modified dynamics with similar flow depths on the upstream and downstream side. In contrast, impervious buildings generate a considerable difference in flow depth. Measurements in Fig. 11a showed flow depths that were 35\% lower for a total porosity of $P_{\text {tot }}=60 \%$ and a rough bed, as compared to the impervious building. These features were similar to those observed for the smooth bed (Wüthrich et al. $(2018 b, c)$ ).

\subsection{Horizontal forces}

The impact of tsunami-like waves on buildings generates forces and moments in all 3 directions. Wüthrich et al. (2018b) showed that horizontal forces in the $x$-direction $\left(F_{\mathrm{x}}\right)$ and moments around the $y$-axis $\left(M_{\mathrm{y}}\right)$ are predominant. For this, loadings in all other directions are herein neglected. The effect of an enhanced bed roughness on the resulting hydrodynamic force is addressed herein, showing differences as compared to the smooth bed. Forces generated by a dry bed surge and a wet bed bore propagating on rough bed impacting on an impervious building are presented in Fig. 12. For surges on rough bed a delayed impact resulting from the slower wave front celerity $U$ is observed. The

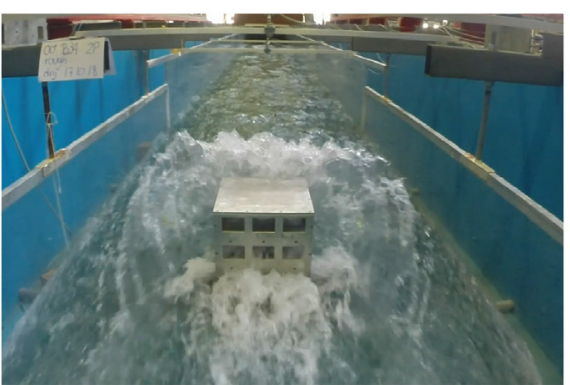

(a) Impact phase

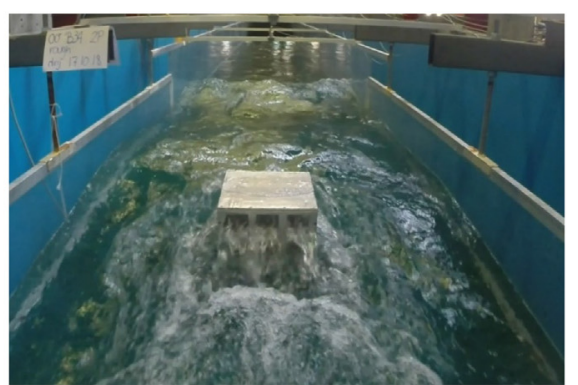

(b) Post-peak steady flow

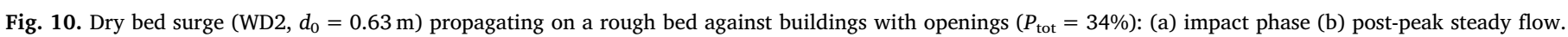




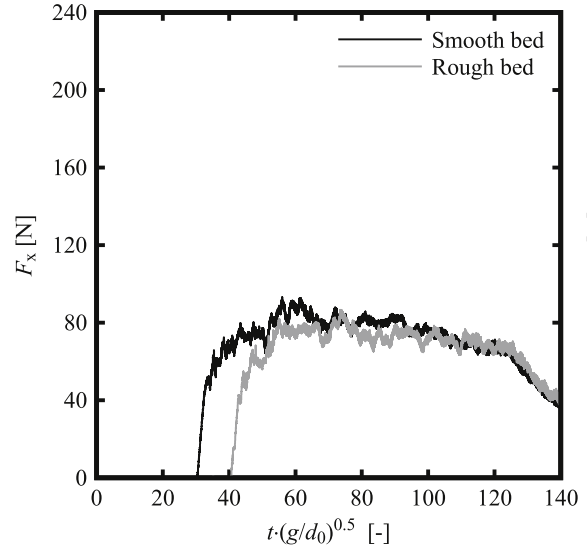

(a)

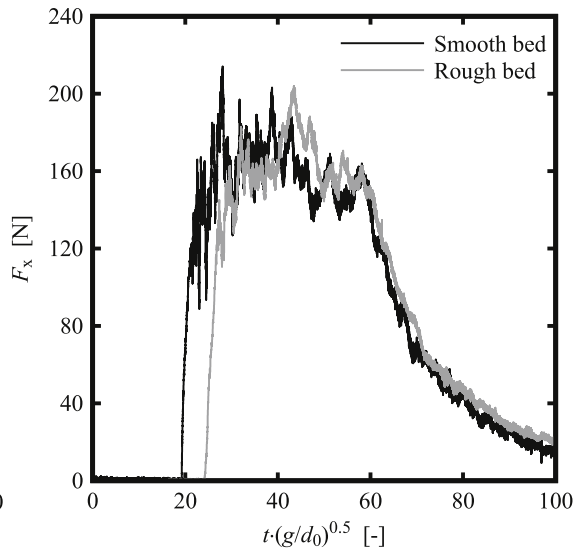

(b)

Fig. 12. Force profiles on impervious free-standing building for dry bed surges propagating over smooth and rough beds: (a). $d_{0}=0.40 \mathrm{~m}$; (b) $d_{0}=0.63 \mathrm{~m}$.

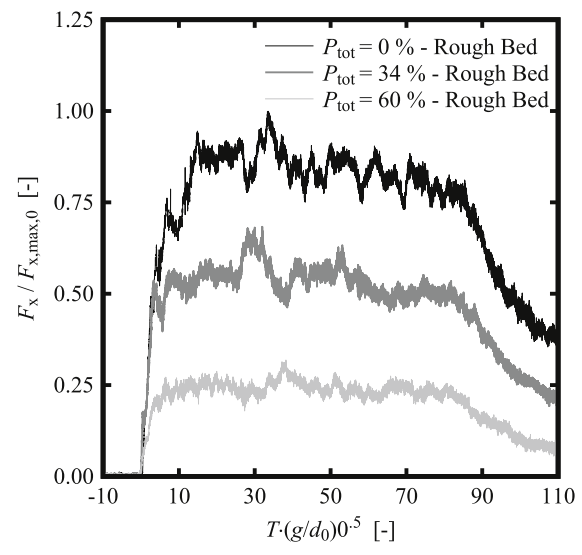

(a) $d_{0}=0.40 \mathrm{~m}$

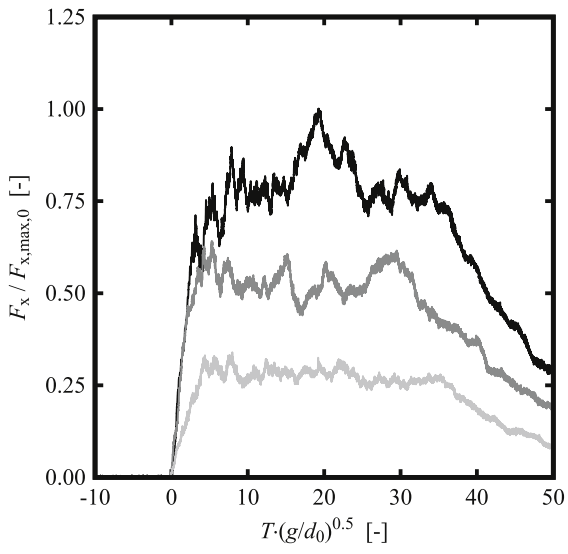

(b) $d_{0}=0.63 \mathrm{~m}$

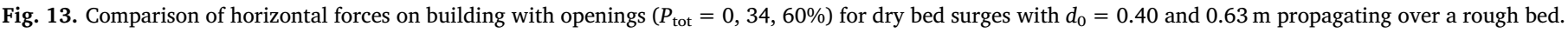
(legend applies to both figures).

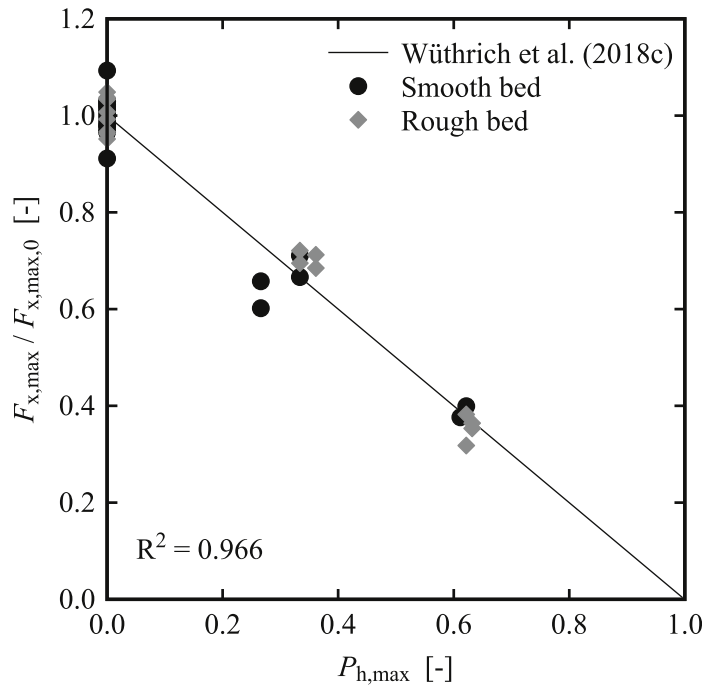

Fig. 14. Normalized force maxima versus building porosity. Experimental data for rough bed are compared with Wüthrich et al., 2018c for buildings with openings on a smooth channel.

convergence of both smooth and rough bed tests during the post-peak hydrodynamic phase is consistent with the numerical simulations of Asadollahi et al. (2019). The loading process showed maximum horizontal forces $F_{\mathrm{x}, \text { max }}$ being 5-10\% lower for the rough bed configuration as compared to the smooth bed (Fig. 15a). This confirms that the induced horizontal forces are tightly linked to the wave momentum flux $h V_{\mathrm{m}}^{2}$ (Table 1). Moreover, the overall loading process takes place during a shorter time period, thus indicating that lesser impulse is transferred to the building for the rough bed (Section 4.3).

The effect of building openings on the resulting horizontal forces was also tested for dry bed surges on rough bed (Table 1). The temporal evolution of the horizontal force $F_{\mathrm{x}}$ is exemplarily shown in Fig. 13 for the impervious building $\left(P_{\text {tot }}=0 \%\right)$ and two additional porosities $\left(P_{\text {tot }}=34 \%\right.$ and $\left.60 \%\right)$. Results show that openings generate a reduction of $F_{\mathrm{x}}$, with features similar to the smooth bed configuration (Wüthrich et al. (2018c)).

The absolute force maxima $F_{\mathrm{x} \text {,max }}$ per test were isolated and plotted in Fig. 14 versus $P_{\mathrm{h}, \max }$, i.e. the cumulative porosity value up to $h=h_{\text {max }}$. All values are normalized using the corresponding maximum force measured for the impervious building $\left(F_{\mathrm{x}, \max , 0}\right)$. Results were compared to Wüthrich et al. (2018c) (smooth bed), showing good agreement (coefficient of determination $\mathrm{R}^{2}=0.97$ ) even for rough beds.

The average (of all repetitions of identical tests, see Table 1) of all maximum forces measured for the configurations on both smooth and rough bed, with and without openings, are compared in Fig. 15a. Globally, the maxima on the rough bed are around 10\% below those of the smooth bed, associated with the lower values of the momentum flux $h V_{\mathrm{m}}{ }^{2}$ in Table 1. This supports the findings of Yeh (2007) and Wüthrich et al. (2018b), suggesting a direct relationship between the wave momentum flux and the load exerted on the building. 


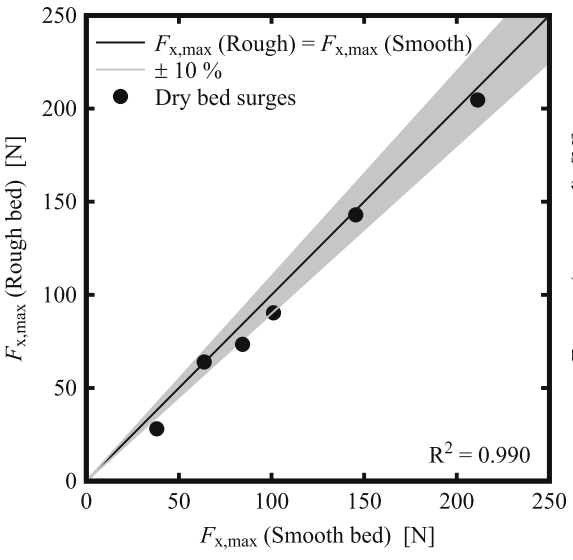

(a)

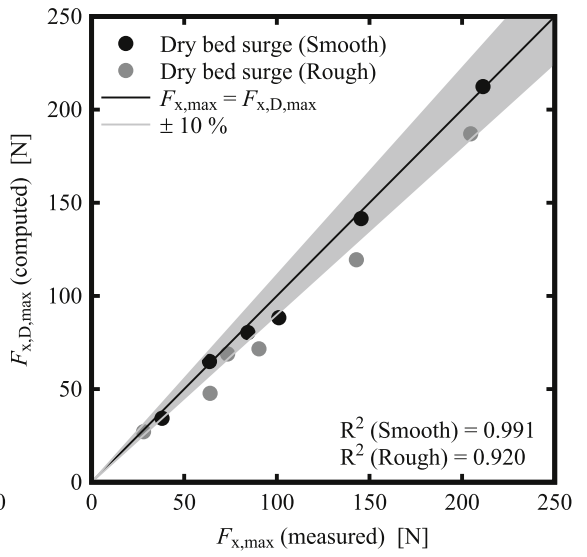

(b)

Fig. 15. Comparison of (a) measured force maxima for smooth and rough beds, and (b) experimental data with predictions according to Eq. (5).

The experimental maxima ( $F_{\mathrm{x}, \max }$, measured) are also compared to those predicted using the hydrodynamic wave properties in Table 1 through Eq. (5)). ( $F_{\mathrm{x}, \mathrm{D} \text {, max }}$, computed). Results showed relatively good agreement within a confidence interval of $10 \%$, suggesting that they key parameters during the impact are the hydrodynamic properties of the propagating waves.

\subsection{Impulse}

The product of force $F$ and time $t$ is known as Impulse $I$, calculated as:

$I_{\mathrm{tot}}=\int_{0}^{150 \sqrt{\frac{d_{0}}{g}}} F_{\mathrm{x}}(T) \mathrm{d} T$

a fixed interval of $\Delta T=150 \cdot\left(d_{0} / g\right)^{0.5}$ was chosen as it included a time interval sufficiently long to cover the whole passage of the wave for both smooth and rough beds. Note that $T$ represents the wave arrival time at the measurement location $\left(T=t-t_{0}\right)$. According to Newton's 2nd Law $(F=m \cdot a=m \cdot \Delta V / \Delta t)$, impulse can be expressed as $I=$ $F \cdot \Delta t=m \cdot \Delta V$, corresponding to the exchange in momentum between the building and the wave. The impulse formulation has the advantage of being less influenced by fluctuations as compared to the maximum force $F_{\mathrm{x}, \max }$ (Bullock et al. (2007)). The impulses computed from both, smooth and rough bed tests, are compared in Fig. 16a. They show relatively seen lower values for rough beds. This is attributed to the higher energy dissipation within the flow on rough beds, leading to shorter impact duration (Fig. 16a).

The linear effect of porosity on the impulse, as it was observed before for the maximum force (Fig. 14), remains and is visualized in Fig. 16b. This confirms that Eq. (6). is also valid for waves propagating on rough bed.

\subsection{Moment and cantilever arm}

Wüthrich et al. (2018b,c) showed that on a smooth bed both force and moment maxima occurred simultaneously. Despite some scattering, Fig. 17a shows a similar trend for the wave impact with a rough bed. This implies that the application point of the force, i.e. the cantilever arm, is

$L_{\mathrm{z}}=\frac{M_{\mathrm{y}, \max }}{F_{\mathrm{x}, \max }}$

The values of $L_{\mathrm{z}}$ obtained for the rough beds were compared to those for the smooth bed. In magnitude, the dimensional values of $L_{\mathrm{z}}$ for the rough bed were comparable to those for the smooth bed. However, given the higher wave heights $h_{\max }$ of the surges propagating on rough beds, this led to smaller relative values of $L_{\mathrm{z}} \approx 0.90 h_{\text {max }}$ for rough beds, as compared to the value $L_{\mathrm{z}}=1.15 h_{\max }$ suggested by Wüthrich et al. (2018b) for smooth beds. For highly unsteady flows, the constant behaviour of $L_{\mathrm{z}}$ as a function of $P_{\mathrm{h} \text {,max }}$ indicates little dependence of the cantilever arm on the building openings, confirming the previous findings on smooth bed.

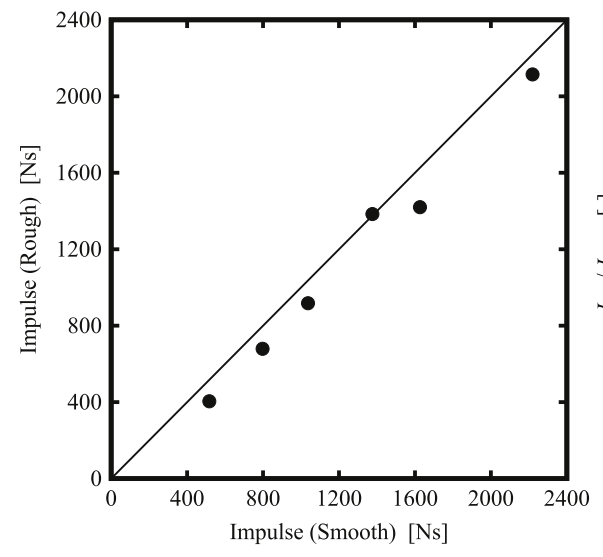

(a)

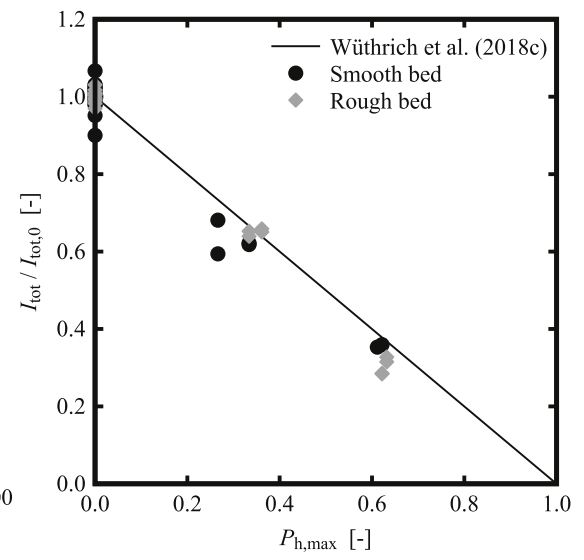

(b)

Fig. 16. Impulse: (a) average values for each configuration tested on smooth and rough bed; (b) variation of the impulse as a function of building porosity. 


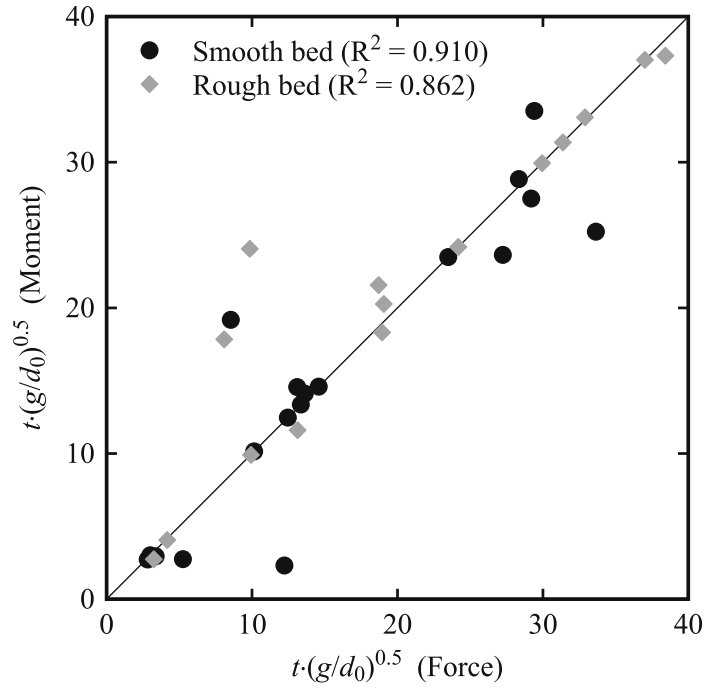

Fig. 17. -Time occurrence of maximum moments $M_{\mathrm{y}, \max }$ and forces $F_{\mathrm{x}, \max }$ for both, smooth and rough beds.

\section{Conclusions}

This experimental study focused on the effect of bed roughness on the hydrodynamic properties of dry bed surges and on their consequent impact on buildings with and without openings. Whilst most previous studies were performed on smooth (and horizontal) channel beds, an enhanced bed roughness was additionally tested herein. The latter represents a more accurate representation of coastal areas subject to tsunami hazard. These surges propagated on both a smooth $(f=0.02)$ and a rough bed $(f=0.04)$. Differences in terms of their hydrodynamic behaviour and impact loads were recorded. The following conclusions can be drawn:

- For dry bed surges, simulating the first incoming tsunami wave, an enhanced bed roughness reduced the wave front celerity, best described by $U=\alpha \cdot\left(g d_{0}\right)^{0.5}$ with $\alpha=1.0$ for $f=0.04$, rather than $\alpha=1.25$ for $f=0.02$. This resulted into a delayed propagation, as compared to the corresponding scenario on smooth bed. However, dry bed surges on rough bed resulted into comparatively higher flow depths.

- In agreement with previous findings on smooth bed, velocity profiles behind the surge front showed a Prandtl power law profile. However, the rougher channel bed generated a thicker boundary layer as compared to the smooth bed.

- The enhanced roughness was associated with a reduction of the momentum flux $h V_{\mathrm{m}}{ }^{2}$ up to $17 \%$ as compared to the smooth configuration.

- These different hydrodynamic properties altered some features of the impact. Due to the lower wave front celerity and higher aeration, lesser splashes were observed on rough bed, however, local flow depths were some $20 \%$ higher, implying that vertical shelters should be taller to avoid building overtopping.

- In terms of horizontal forces, the lower values of the momentum flux $h V_{\mathrm{m}}{ }^{2}$ associated with the waves on rough bed, resulted in force maxima about $10 \%$ lower than the corresponding configuration on smooth bed.

- The effect of openings on impact forces was linear for the rough bed, thus proving that the linear model suggested by Wuithrich et al. (2018c) for the smooth configuration can also be applied in case of rough bed.

- The duration of the impact was shorter for the rough bed, thus resulting into lesser impulse transferred from the wave to the building.

- The total horizontal forces were applied with cantilever arms comparable to the smooth bed, however because of the higher wave heights, the ratio $L_{z} / h_{\max }$ was 0.9 instead of 1.15 , as suggested by Wüthrich et al. (2018b) for smooth beds.

These results showed that a structural design based on wave impact forces generated on a smooth horizontal bed represents globally a conservative approach. However, for vertical shelters, inundation depths should consider the effect of bed roughness.

\section{Acknowledgment}

This research was conducted as part of the ENATIS project (Experimental-Numerical Approach for Tsunami Impact on Structures) cofounded by LCH-EPFL and JAMSTEC. This research was supported by the Swiss National Science Foundation (SNSF) [grant numbers 200021_149112/1, 200021_149112/2 (Anton Schleiss) and P2ELP2_181794 (Davide Wüthrich)]. The authors would like to acknowledge Ms Clàudia Ylla Arbós (EPFL) for conducting the experimental tests related to rough bed, and Dr. Giovanni De Cesare (EPFL) for his advice.

\section{List of symbols}

$B \quad$ building transversal width, $B=0.3[\mathrm{~m}]$

$b \quad$ empirical constant in Eq. (3)

$c \quad$ empirical constant in Eq. (3), $c=0.3$

$C_{\mathrm{R}} \quad$ resistance coefficient for the impervious, reference building, $C_{\mathrm{R}}=2.0$

$d_{0} \quad$ equivalent impoundment depth for dam-break wave[m]

$f \quad$ Darcy-Weisbach friction factor

F force [N]

Fr Froude number, $\mathbf{F r}=U /\left(g h_{\max }\right)^{0.5}$

$g \quad$ gravity constant, $g=8.91\left[\mathrm{~m} / \mathrm{s}^{2}\right]$

$h \quad$ wave height without the building [m]

$h_{\mathrm{i}} \quad$ wave height of profile $i[\mathrm{~m}]$

$H \quad$ flow depth with the building [m]

I impulse [Ns]

$I_{\text {tot }} \quad$ total impulse [Ns]

$L_{\mathrm{z}} \quad$ cantilever arm, Eq. (8) [m]

$m$ mass $[\mathrm{kg}]$

$M_{\mathrm{y}} \quad$ moment around the $y$-axis [Nm]

$M \quad$ momentum flux per unit width, $M=h V_{\mathrm{m}}{ }^{2}\left[\mathrm{~m}^{3} / \mathrm{s}^{2}\right]$

n exponent

$P_{\mathrm{h}, \max } \quad$ cumulative building porosity at $h=h_{\max }[\%]$

$P_{\text {tot }} \quad$ total building porosity [\%]

$T \quad$ shifted time, $T=t-t_{0}[\mathrm{~s}]$

$t \quad$ time [s]

$t_{0} \quad$ wave arrival time at measurement location [s]

$U \quad$ wave front celerity $[\mathrm{m} / \mathrm{s}]$

$V \quad$ wave velocity $[\mathrm{m} / \mathrm{s}]$

$V_{\mathrm{m}} \quad$ depth-averaged velocity (Eq. (3)) $[\mathrm{m} / \mathrm{s}]$

$W \quad$ channel width, $W=1.4[\mathrm{~m}]$

$x \quad$ longitudinal streamwise coordinate [m]

$\alpha \quad$ celerity coefficient (Eq. (1))

$\beta \quad$ blockage ratio, $\beta=W / B$

$\Pi \quad$ porosity coefficient defined in Eq. (6)

$\rho \quad$ water density, $\rho=1000\left[\mathrm{~kg} / \mathrm{m}^{3}\right]$

Subscripts

$0 \quad$ reference impervious building

D predicted, computed

$\max$ maximum value

$x \quad x$ direction

$y \quad y$ direction 


\section{References}

Arnason, H., Petroff, C., Yeh, H., 2009. Tsunami bore impingement onto a vertical column. J. Disaster Res. 4 (6), 391-403.

Asadollahi, D., Nistor, I., Mohammadian, A., 2019. Numerical investigation of tsunami bore effects on structures, part II: effects of bed condition on loading onto circular structures. Nat. Hazards 96 (1), 331-351.

Asakura, R., Iwase, K., Ikeya, T., Takao, M., Kaneto, K., Fujii, N., Omori, M., 2000. An experimental study on wave force acting on on-shore structures due to overflowing tsunamis. Proc. Coast. Eng. Conf. 47, 911-915 (in Japanese).

ASCE7-6 (Structural Engineering Institute), 2016. Minimum Design Loads for Buildings and Other Structures. ASCE/SEI 7-16. Reston, VA.

Baldock, T., 2018. Bed shear stress, surface shape and velocity field near the tips of dambreaks, tsunami and wave runup" by Peter Nielsen. Coast. Eng. 142, 77-81.

Bryant, E., 2008. Tsunami: the Underrated Hazard. Springer, Berlin.

Bullock, G., Obhrai, C., Peregrine, D., Bredmose, H., 2007. Violent breaking wave impacts. part 1: results from large-scale regular wave tests on vertical and sloping walls. Coast. Eng. 54 (8), 602-617.

CCH (City and County of Honolulu), 2000. City and County of Honolulu Building Code (Chapter 16), Article 11. Honolulu, HI.

Chanson, H., 2004. The Hydraulics of Open Channel Flow: an Introduction. Elsevier, Oxford, pp. 585.

Chanson, H., 2006. Tsunami surges on dry coastal plains: application of dam break wave equations. Coast Eng. J. 48 (4), 355-370 2006.

Chanson, H., 2009. Application of the method of characteristics to the dam break wave problem. J. Hydraul. Res. 47 (1), 41-49.

Chanson, H., Aoki, S., Maruyama, M., 2002. Unsteady air bubble entrainment and detrainment at a plunging breaker: dominant time scales and similarity of water level variations. Coast. Eng. 46 (2), 139-157.

Chock, G., Robertson, I., Kriebel, D., Francis, M., Nistor, I., 2012. Tohoku Japan Tsunami of March 11, 2011 - Performance of Structures. American Society of Civil Engineers ASCE, pp. 348

Choufi, L., Kettab, A., Schleiss, A.J., 2014. Effet de la rugosité du fond d'un réservoir rectangulaire à faible profondeur sur le champ d'écoulement. La Houille Blanche 5, 83-92.

Cross, R., 1967. Tsunami surge forces. J. Waterw. Harb. Div. 93 (4), 201-231.

Dressler, R.F., 1952. Hydraulic resistance effect upon the dam-break functions. J. Res. Natl. Bur. Stand. 49 (3), 217-225 1952.

Dressler, R.F., 1954. Comparison of theories and experiments for the hydraulic dam-break wave. Int. Assoc. Sci. Hydrol. 3 (38), 319-328.

FEMA55, 2000. Coastal Construction Manual. Federal Emergency Management Agency, Washington DC, USA.

Foster, A.S.J., Rossetto, T., Allsop, W., 2017. An experimentally validated approach for evaluating tsunami inundation forces on rectangular buildings. Coast. Eng. 128, 44-57.

Fritz, H.M., Okal, E.A., 2008. Socotra island, Yemen: field survey of the 2004 Indian Ocean tsunami. Nat. Hazards 46 (1), 107-117.

Iizuka, H., Matsutomi, H., 2000. Damage due to flood flow of tsunami. Proc. Coast. Eng. JSCE 47, 381-385.

Kirkoz, M., 1983. Breaking and run-up of long waves, tsunamis: their science and engineering. In: Proceedings of the 10th IUGG International Tsunami Symposium. Terra Scientific, Tokyo.

Lukkunaprasit, P., Ruangrassamee, A., Thanasisathit, N., 2009. Tsunami loading on buildings with openings. Sci. Tsunami Hazards 28 (5), 303.

Madsen, P., Fuhrman, D., Schäffer, H., 2008. On the solitary wave paradigm for tsunamis.
J. Geophys. Res.: Oceans 113 (C12) 1978-2012.

Matsutomi, H., Okamoto, K., 2010. Inundation flow velocity of tsunami on land. Isl. Arc 19 (3), 443-457.

Meile, T., Boillat, J.L., Schleiss, A.J., 2011. Water-surface oscillations in channels with axi-symmetric cavities. J. Hydraul. Res. 49 (1), 73-81.

Murty, T.S., 1977. Seismic Sea Waves: Tsunamis. Department of Fisheries and the Environment Fisheries and Marine Service, Ottawa.

Nielsen, P., 2018. Bed shear stress, surface shape and velocity field near the tips of dambreaks, tsunami and wave runup. Coast. Eng. 138, 126-131.

Nistor, I., Palermo, D., Nouri, Y., Murty, T., Saatcioglu, M., 2009. Tsunami-induced forces on structures. In: Handbook of Coastal and Ocean Engineering. World Scientific, Singapore, pp. 261-286.

Nouri, Y., Nistor, I., Palermo, D., Cornett, A., 2010. Experimental investigation of tsunami impact on free standing structures. Coast Eng. J. 52 (1), 43-70.

Ramsden, J.D., 1996. Forces on a vertical wall due to long waves, bores, and dry-bed surges. J. Waterw. Port, Coast. Ocean Eng. 122 (3), 134-141.

Ritter, A., 1892. Die Fortpflanzung der Wasserwellen. Zeitschrift Verein Deutscher Ingenieure 36 (33), 947-954 1892.

Rossetto, T., Allsop, W., Charvet, I., Robinson, D., 2011. Physical modelling of tsunami using a new pneumatic wave generator. Coast. Eng. 58 (6), 17-527.

Rossetto, T., Peiris, N., Pomonis, A., Wilkinson, S.M., Del Re, D., Koo, R., Gallocher, S., 2007. The Indian Ocean tsunami of December 26, 2004: observations in Sri Lanka and Thailand. Nat. Hazards 42 (1), 105-124.

Shafiei, S., Melville, B.W., Shamseldin, A.Y., 2016. Experimental investigation of tsunami bore impact force and pressure on a square prism. Coast. Eng. 110, 1-16.

Stoker, J.J., 1957. Water waves: the mathematical theory with applications. Intersciences 567.

Thusyanthan, N., Madabhushi, S., 2008. Tsunami wave loading on coastal houses: a model approach. Civ. Eng. 161 (2), 77-86.

Whitham, G., 1955. The effects of hydraulic resistance in the dam-break problem. Proc. Roy. Soc. Lond. Math. Phys. Sci. 227 (1170), 399-407.

Wilson, J., Gupta, R., Van de Lindt, J., Clauson, M., Garcia, R., 2009. Behavior of a onesixth scale wood-framed residential structure under wave loading. J. Perform. Constr. Facil. 23 (5), 336-345.

Wüthrich, D., Pfister, M., Nistor, I., Nistor, I., Schleiss, A.J., 2017. Estimation of wave propagation velocity on a channel with smooth and rough bed. In: 37th IAHR World Congress, Kuala Lumpur, Malaysia, 13-18 August.

Wüthrich, D., Pfister, M., Nistor, I., Schleiss, A.J., 2018a. Experimental study of tsunamilike waves generated with a vertical release technique on dry and wet beds. ASCE Journal of Waterways, Port Coast. Ocean Eng. 144 (4), 04018006.

Wüthrich, D., Pfister, M., Nistor, I., Schleiss, A.J., 2018b. Experimental study on the hydrodynamic impact of tsunami-like waves against impervious free-standing buildings. Coast Eng. J. 60 (2), 180-199.

Wüthrich, D., Pfister, M., Nistor, I., Schleiss, A.J., 2018c. Experimental study on forces exerted on buildings with openings due to extreme hydrodynamic events. Coast. Eng. 140, 72-86.

Wüthrich, D., Pfister, M., Nistor, I., Schleiss, A.J., 2019. Effect of building's overtopping on induced loads during extreme hydrodynamic events. J. Hydraul. Res. https://doi org/10.1080/00221686.2019.1573764. published online.

Yeh H., H., 2007. Design tsunami forces for onshore structures. J. Disaster Res. 2 (6), 531-536.

Ylla Arbós, C., Wüthrich, D., Pfister, M., Schleiss, A.J., 2018. Wave impact on oriented impervious buildings. In: Proceedings of the 5th IAHR Europe Congress, Trento, Italy, 12-14 June. 